\title{
Comparison of AMMI and GGE Biplot Analysis to Assess the Adaptability and Stability of Bt Cotton Genotypes
}

\author{
Ashwini N.R. Samak ${ }^{1 *}$, S. Rajeswari², R. Ravikesavan ${ }^{2}$, \\ N. Subbalakshmi Lokanadhan ${ }^{2}$, Ganapathy ${ }^{2}$ and A.V. Kini ${ }^{1}$ \\ ${ }^{1}$ Indo-American Hybrid Seeds (I) Pvt Ltd, Bangalore, Karnataka, India \\ ${ }^{2}$ Department of Cotton, Centre of Plant Breeding \& Genetics, \\ Tamil Nadu Agricultural \\ University, Coimbatore, India
}

\section{A B S T R A C T}

\begin{tabular}{|c|}
\hline Keywords \\
\hline $\begin{array}{l}\text { Bt cotton, } \\
\text { GEI, } \\
\text { AMMI, } \\
\text { GGE biplot }\end{array}$ \\
\hline Article Info \\
\hline $\begin{array}{l}\text { Accepted: } \\
18 \text { August } 2020 \\
\text { Available Online: } \\
10 \text { September } 2020\end{array}$ \\
\hline
\end{tabular}

Development of high yielding, genetically stable Bt-cotton hybrid has been a priority in cotton breeding. Popular biometric tools such as AMMI and GGEbiplot analyses were compared to identify the stability of cotton hybrids for seed cotton yield across three locations in India. Both models showed significant variances for seed cotton yield due to genotypes $(\mathrm{G})$, environment (E ) and GE interaction The AMMI model treated three environments (Aurangabad, Raichur and Dharwad) as very distinguishing by, whereas the GGE-biplot considered them as two mega environments (ME) with Aurangabad and Raichur as similar. Stable hybrids identified from both the statistical biometric tools were also differing. The AMMI analysis indicated that IAHH-8102 BGI, IAHH-8006 BGII and IAHH8005 BGII were found to be promising hybrids, whereas IAHH-8039 BGI, IAHH8041BGI and IAHH-8046 BGII found to be stable in GGE analysis. Although both methods efficiently diagnosed the interaction and stability, GGE Biplot was more user-friendly approach in identification of hybrids without compromising the yield parameters.

\section{Introduction}

Bollworm-resistant cotton, is popularly known as $B t$ cotton has been the most preferred technology in the major cotton growing countries in the world. Globally transgenic $B t$ Cotton is grown under 18.4 million hectares in fifteen countries (ISAAA, 2018). Bt cotton cultivar forms can be classified as $B t$ lines/varieties and hybrids derived crossing two cotton lines. In India, $95 \%$ of the cotton area is covered by $B t$ cotton hybrids. Development of genetically stable $\mathrm{Bt}$ cotton cultivars has been a priority for cotton breeding. Commercial seed companies are aiming at the development of hybrids with high yield and wider adaptability in such case, effective multi-environment testing (MET) 
and better handling of data assumes significant importance to select best performing hybrids across diverse environments. Most of the published studies on stability analysis in cotton have used Non$\mathrm{Bt}$ cotton hybrids or varieties, which were susceptible to bollworms, required insecticide applications and complex management practices. In such studies involving Non $\mathrm{Bt}$ cotton hybrids, the total variance due to environments also included the degree of bollworm infestation that was very seasonal and differed in each of the environments and contributed to environmental variation. In the current study, we have used $B t$ cotton hybrids materials (Bollworm resistant) to nullify the bollworm damage and no insecticidal applications were made for managing the bollworms. In such situation differences in the environments were mostly due to soil, weather and agronomic practices that any way varies with geographies and adoption of promising hybrids to these diverse environments is of key interest for the commercial success of hybrids.

The GE interaction that results from the differential responses of genotypes across a range of environments reduces the correlation between phenotypic and genotypic values and complicates the selection of the best genotypes (Ebdon and Gauch, 2002). Studies indicated that evaluation of the test locations for genotypes suitability in multi-environment varietal trials areof critical relevance because it checks the extent to which selected test locations are representative of the whole target region (Baxevanos et al., 2008). This helps to improve breeding effectiveness and reduce costs if only those locations that have a proper capability to discriminate between genotypes under selection are used in the variety of trials (Blanche and Myers, 2006; Yan et al., 2007).

Scientists have used different statistical tools to find the nature of genotypic interactions with the environments. Among these statistical techniques, two frequently used are multivariate analysis models are additive main effects and multiplicative interaction (AMMI) and genotype main effects and genotype by environment interaction (GGE) models. For the accurate analysis of METs, AMMI model is a valuable tool due to the accuracy that it provides in GE interaction studies (Li et al., 2006). AMMI analysis combines the additive parameters of traditional ANOVA with multiplicative parameters of PCA (principal component analysis). Another method GGE biplot, uses a biplot to show the factors (G and GE) that are important in genotype evaluation and sources of variation in GE interaction (Yan et al., 2000). The GGE- biplot is constructed by the first two principal components (PC1 and PC2) derived from subjecting environment centered yield data to singular value decomposition. It clearly shows which genotype won in which environments and thus facilitates megaenvironments (MEs) identification (Yan et al., 2000). The AMMI and GGE biplot models are defined as powerful tools for effective analysis and interpretation of multienvironment data structure in breeding programs (Ebdon and Gauch, 2002; Samonte et al., 2005). The AMMI and GGE biplot have frequently been used for explaining GE interaction and to identify high yielding and adapted cultivars (Riaz et al., 2019).

The aim of the present research was to know about the GXE interaction and stability of newly developed drought tolerantBt cotton hybrids using GGE and AMMI biplot analysis for the seed cotton yield, in order to find stable hybrids across the environments.

\section{Materials and Methods}

\section{Plant material and planting}

The experiments were conducted during 2018 kharif season with a set of 105 hybrids 
comprising of 69 BG II (MON15985 event), 34 BG I (MON 531 event) and two each of Non-Bt hybrids along with BG II and Non-Bt hybrids used as a check. During 2018, the replicated randomised block design trials were conducted in three locations situated in Dharwad and Raichur, Karnataka and Aurangabad, Maharashtra India during the rainy season 2018 managed by Indo American Hybrid Seeds(I), Pvt. Ltd. Details of the diverse environments are given in Table 1. The recommended packages of practices to those locations were followed. The plot size was maintained by two rows of $9 \mathrm{~m}$ length of 10 dibbles spacing of $90 \mathrm{~cm}$ row to row and $90 \mathrm{~cm}$ between plant to plant.Observations on seed cotton yield $\mathrm{Kg} / \mathrm{plot}$ in all the replications were measured and data were later converted in $\mathrm{kg} / \mathrm{ha}$.

\section{Statistical analysis}

Data were subjected to AMMI and GGE biplot analysis by PB Tools version 1.4 developed by International Rice Research Institute, Philippines (PB Tools 2014). In Multiplicative stability model, AMMI the analysis includes ANOVA and PCA in a unified approach that can be used to analyze multiple yield trials (Crossa et al., 1990; Gauch and Zobel, 1996). AMMI uses ANOVA to test the main effects of genotypes and environments, and PCA to analyze the residual multiplicative interaction between genotypes and environments to determine the sum of squares of the $\mathrm{G} \times \mathrm{E}$ interaction, with a minimum number of degrees of freedom. Since AMMI does not provide a quantitative measurement, it is necessary to quantify and rank genotypes and based on their yield. AMMI Stability Value (ASV), length of genotype and environment markers of the origin in a two-dimensional plot of IPCA1 scores against IPCA2 scores were calculated according to Purchase et al., (2000) .Yield Stability Index (YSI) incorporates both mean yield and stability in a single criterion. The minimum values of YSI desirable genotypes with high mean yield and stability.

GGE biplot displays the $G$ and $G E$ of genotype-by-environment data. The key property of a GGE biplot is that it is based on Tester centered data, whereby the environment main effects (E) are removed, and the entry main effect $(\mathrm{G})$ and the entry by interaction (GE) are retained and combined. Therefore, a biplot based on tester- centered data contains only G+GE, shortened as GGE. In GGE-Biplot analysis, test location evaluation is conducted graphically (Yan and Holland 2010).

\section{Results and Discussion}

\section{AMMI analysis}

Analysis of variance of AMMI model was highly significant for genotype, environment and Genotype $\mathrm{x}$ Environment Interaction (GEI) effects $(\mathrm{p}<0.001)$ for seed cotton yield (Table 2) indicating differences between testing locations and also between the of $\mathrm{Bt}$ cotton hybrids. Sum of squares of genotype $(41 \%)$ and environment (39.6\%) were almost double of the GEI variance $(19 \%)$ indicates the most of the genotypes were diverse and stable across the location (irrespective of seed cotton yield) and environments are diverse.

The GEI in AMMI model explained by PCA1 $\left(\mathrm{SS}{ }_{\mathrm{PCA} 1}=52.12 \%\right)$ and $\mathrm{PCA} 2$ (SS ${ }_{\mathrm{PCA} 2}=$ $47.88 \%$ ) were highly significant. The same results were observed by Orawu et al., 2017 and Tena et al., 2019. The first principal component SS is more than the sum of squares of genotypes and same was noticed in Riazet al., 2013 in cotton.

AMMI (model 2) biplot was plotted using IPCA1 scores and means of environment and cotton hybrids (Figure 1). The test locations 
like Dharwad and Aurangabad were plotted on right-hand side of the midpoint of the main effect axis regardless of IPCA scores indicate them as high productive environments for seed cotton yield, on the contrary Raichur location was plotted left hand side reflecting low productive environment (Riaz et al., 2013). Scores with same sign or near to zero represent a non-crossover GE interaction (Yan and Hunt 2001, Mohammadi et al., 2007). Scores with different signs drifting away from zero are non-cross over types. This disproportionate genotype response is referred as GE interaction for convenience (Mohammadi et al., 2007). Among the 109 cotton hybrids evaluated, 55 hybrids were classified as non-crossover type as they had same signs of IPCA values and plotted near to zero and 54 hybrids were cross over types with different signs of IPCA values and drifted away from zero. Of the 55 non cross over hybrids, frequency of high average yielding (more than average yield) hybrids (27) was comparable to low average yielding (28), however, high average yielding (25) hybrid frequency was less than lower than average yielding (29) in cross over hybrids. Distribution of cross over and non-cross over among different biotech trait hybrids were almost equal in BGII, BGI and Non Bt hybrids and similar was the distribution of high average yielding hybrids in each class with an exception that none of the Non Bt hybrids were high yielding (Table 3 ). This largely reflects the presence of $\mathrm{BG} I$ (MON531 event) and BG II (MON 15985 event) have no relationship on the stability of the cotton hybrids. Based on graphical biplot seven hybrids (5 BG II and 2 BG I) IAHH8061 BG II, IAHH -8092 BG II, IAHH -8041 BG I, IAHH- 8054 BG II, IAHH -8052 BG II, IAHH -8075 BG I, IAHH- 8103 BG II were found to be ideal cotton hybrids as they were high yielding and plotted near to axis. In the study, it was clear that Bt cotton hybrids had higher yield levels compared to non-Bt cotton hybrids and in overall situation BG I hybrids were more promising than BG II. However, hybrids varied for stability pattern reflecting that $\mathrm{Bt}$ gene only contributes recovery of losses due to bollworms and makes it higher yielding and has no contribution to the stable performance of the hybrids. Actual yield potential of the hybrids is the genetic constitution of the hybrid per se and the presence of yield contributing characters in it, which vary with environment.

\section{AMMI stability value and yield stability index}

Since AMMI analysis will not quantify the stability of the hybrid, mean yield and ASV values were considered to predict the stability of hybrid over environment. Yield stability Index used to know the performance of hybrid and stability. The least YSI is considered as the most stable with high yielding hybrids (Alemu et al., 2019). Based on YSI most stable with high seed cotton yielding hybrids are, IAHH-8102 BG I, IAHH-8007 BG II, IAHH-8006 BG II , IAHH-8061 BG II, IAHH-8096 BG II, IAHH-8001 BG II, IAHH-8040 BG I, IAHH-8092 BG II and IAHH-8041 BG I with YSI values of 16,36 , 41, 41, 45, 25, 50,52, 53 respectively. Among most stable with high seed cotton yielding IAHH-8078 BG I, IAHH-8102 BGI and IAHH-8040 BG I were crossover with high seed cotton yielder whereas, IAHH-8007 BG II, IAHH-8006 BG II, IAHH-8061 BG II , IAHH-8096 BG II, IAHH-8001 BG II, IAHH-8092 BG II and IAHH-8041 BG I were non crossover types with high seed cotton yield hybrids (Table 4).

\section{GGE biplot analysis}

In plant breeding, GGE biplot has been known as an innovative methodology in biplot graphical analysis. GGE biplot is an effective tool for: 1) mega environment 
analysis ("which-won-where" pattern), whereby specific genotypes can be recommended to specific mega-environments; 2) genotype evaluation (the mean performance and stability), and 3) environmental evaluation (the power to discriminate among genotypes in target environments) (Yan and Kang, 2003).The GGE biplot explained $91.9 \%$ of total variation by both components with $76.01 \%$ from PC1 and $15.89 \%$ from PC2 which indicate effects of genotype and the interaction of genotype with environment, respectively.

GGE biplot analysis clearly indicated relationship between locations with length of vectors on biplot (Figure 2a and $b$ ). Based on Figure $2 \mathrm{a}$ and $\mathrm{b}$, Aurangabad and Dharwad are more discriminating environments with longer vectors than the Raichur (Yan et al., 2007). Raichur gave short vector indicating the environment is not well represented by PC1 and PC2 indicating all genotypes performed similarly. Aurangabad having long vector and small angle with the AEC abscissa and this will be ideal for selecting superior genotypes. Likewise, all environments were having medium acute angle with abscissa indicating positively relating to environments.

In the "which-won-where" pattern (Figure 3a), biplot was divided into 5 sectors and the three locations were in two vectors with Aurangabad and Raichur (mega environment 1) in one sector and Dharwad (mega environment 2) in another. In Mega environment 1, hybrid -like IAHH-8039 BGI, IAHH-8041 BGI, IAHH-8046 BGII, IAHH8081 BGI, IAHH-8005 BGII, IAHH-8078 BG I, IAHH-8047 BGII, IAHH-8077 BGI, IAHH-8048 BGII, IAHH-8074 BGI and IAHH-8089 BGII were made cluster and indicating the these hybrids were suitable for Mega Environment 1. Likewise, the hybrids IAHH-8084 BG I, IAHH-8049 BGII, IAHH8080 BG I, IAHH-8043 BG II, IAHH-8018
BG I, IAHH-8029 BG II, IAHH-8053 BG II and IAHH-8020 BG I were performed well under Mega Environment 2.

AEC view with Mean vs Stability biplot facilitates genotype comparison based on mean performance and stability across the environment (Figure 3b). According to biplot, eighteen Bt Cotton hybrids were plotted from ideal genotype to last concentric circle based on mean performance and stability of the hybrids. It is demonstrated that hybrid IAHH$8039 \mathrm{BGI}$ is in the central circle and therefore possesses high stability and performance. Accordingly, IAHH-8081 BGI, IAHH-8005 BGII and IAHH-8083 BGI, followed by IAHH-8046 BGII, IAHH-8102 BGI, and IAHH-8082 BGI were placed in the second and third circles, respectively, and were considered as desirable genotypes.

\section{AMMI and GGE Biplot comparison}

In public and private commercial cotton breeding and product development programs of India, average per se performance of hybrids across the locations is considered for promoting candidate hybrids to the next level. We can check about the efficacy biometric tools to know the stability of only high yielding hybrids across locations. In this study, we isolated top 5 high yielding hybrids based on the seed cotton yield and compared their stability with both biometric tools for stability and their usefulness in promotions of hybrids to higher stage (Table 5). AMMI defined four out of five hybrids as crossover type, and very high yielding hybrid (IAHH 8039 BGI) was also cross over type too. On the contrary, IAHH 8039 BGI was an ideal hybrid in the GGE biplot (Fig. 3b) followed by the next high yielding hybrid IAHH 8081 BGI. GGE biplot and this model is likely to provide better information in decision making on hybrid promotions and commercialization. 
Table.1 Geographical coordinates, soil and climatic conditions, and precipitation details of three locations

\begin{tabular}{|c|c|c|c|c|c|c|}
\hline Location & Coordinates & $\begin{array}{c}\text { Koppen climate } \\
\text { classification }\end{array}$ & $\begin{array}{c}\text { Elevation } \\
(\mathbf{m s l})\end{array}$ & Soil & Management & $\begin{array}{c}\text { Annual } \\
\text { rainfall (mm) }\end{array}$ \\
\hline Aurangabad & $\begin{array}{c}19.88^{\circ} \mathrm{N} \\
75.32^{\circ} \mathrm{E}\end{array}$ & Semi Arid (Bsh) & 568 & $\begin{array}{c}\text { Deep black } \\
\text { soil }\end{array}$ & Irrigated & 739 \\
\hline Dharwad & $\begin{array}{c}15^{\circ} 26^{\prime} \mathrm{N} \\
75^{\circ} 07^{\prime} \mathrm{E}\end{array}$ & $\begin{array}{c}\text { Tropical Wet and } \\
\text { Dry climate (Aw) }\end{array}$ & 741 & $\begin{array}{c}\text { Medium } \\
\text { black }\end{array}$ & $\begin{array}{c}\text { Need based } \\
\text { Irrigated }\end{array}$ & 800 \\
\hline Raichur & $16.2^{\circ} \mathrm{N}$ & $\begin{array}{c}\text { Semi Arid to dry } \\
\text { (Bsh) }\end{array}$ & 407 & $\begin{array}{c}\text { Medium } \\
\text { black soil }\end{array}$ & Rainfed & 713 \\
\hline
\end{tabular}

Table.2 Analysis of variance of main effects and interactions (AMMI) for seed cotton yield in cotton hybrids

\begin{tabular}{|c|c|c|c|c|c|}
\hline $\begin{array}{c}\text { Source of } \\
\text { Variation }\end{array}$ & Df & SS & MS & $\begin{array}{c}\text { Variability } \\
\text { explained (\%) }\end{array}$ & $\begin{array}{c}\text { Cumulative } \\
\text { variability (\%) }\end{array}$ \\
\hline Environment & 2 & 140068421.30 & $70034210.65^{* *}$ & 39.56 & 39.56 \\
\hline Genotypes (G ) & 108 & 145996724.50 & $1351821.52 * *$ & 41.23 & 80.79 \\
\hline G X E Interaction & 216 & 68040621.90 & $315002.88^{* *}$ & 19.21 & 100.00 \\
\hline PC1 & 109 & 35462977.35 & $325348.42 * *$ & 52.12 & 52.12 \\
\hline PC2 & 107 & 32577644.54 & $304463.97 * *$ & 47.88 & 100.00 \\
\hline Residuals & 326 & 14534339.16 & 44447.52 & 0 & 0 \\
\hline
\end{tabular}

Table.3 Groupwise hybrid performance and GEI among them for seed cotton yield

\begin{tabular}{|c|c|c|c|c|c|c|c|c|}
\hline Group & $\begin{array}{c}\text { No. } \\
\text { hybrids }\end{array}$ & $\begin{array}{c}\text { Range SCY } \\
\text { (kg/ha) }\end{array}$ & $\begin{array}{c}\text { SCY } \\
\mathbf{( k g / h a )}\end{array}$ & ASV & $\begin{array}{c}\text { Non } \\
\text { cross } \\
\text { over } \\
\text { hybrids* }\end{array}$ & $\begin{array}{c}\text { Cross } \\
\text { overs } \\
\text { hybrids* }\end{array}$ & $\begin{array}{c}\text { YSI } \\
\text { values }\end{array}$ & $\begin{array}{c}\text { Hybrids } \\
\text { having low } \\
\text { YSI score } \\
\text { (YSI rank })\end{array}$ \\
\hline BG II & 71 & $1646-3622$ & 2691 & $0.38-20.06$ & $36(15)$ & $35(15)$ & $36-216$ & $36(2)$ \\
\hline BG I & 34 & $2493-4095$ & 3071 & $0.96-18.11$ & $18(12)$ & $16(10)$ & $16-167$ & $16(1)$ \\
\hline Non bt & 4 & $1738-2324$ & 2086 & $0.39-9.82$ & 1 & 3 & $108-165$ & $108(59)$ \\
\hline
\end{tabular}

Table. 4 Top 5 hybrids and their inference from AMMI and GGE model

\begin{tabular}{|c|c|c|c|c|c|c|c|c|c|c|c|}
\hline \multirow{3}{*}{ SI no } & \multirow{3}{*}{ Hybrids } & \multirow{2}{*}{\multicolumn{2}{|c|}{ CCVPCV }} & \multicolumn{7}{|c|}{ AMMI inference } & \multirow{3}{*}{$\begin{array}{l}\text { GGE inference } \\
\text { Mean V/s Stability } \\
\text { order of hybrids }\end{array}$} \\
\hline & & & & IPCA 1$]$ & IPCA 2 & ASVI & \multicolumn{4}{|c|}{ RASV YSIRank YSIG X E interaction } & \\
\hline & & & & & & & & & & & \\
\hline 1 & IAHH-8039 BG I & {$[4095$} & 1 & -3.96 & 9.28 & 10.16 & 76 & 77 & 22 & Cross over & IAHH-8039 \\
\hline 2 & IAHH-8081 BG I & [ 3774 & 2 & -11.72 & 0.77 & 12.25 & 91 & 93 & 43 & Cross over & BG I $>$ IAHH-8081 \\
\hline 3 & IAHH-8041 BG I & {$[3717$} & 3 & 0.54 & 6.63 & 6.66 & 50 & 53 & 10 & Non cross over & BG I>IAHH-8005 \\
\hline 4 & IAHH-8083 BG I & [ 3625 & 4 & -13.36 & 2.49 & 14.16 & 100 & 104 & 52 & Cross over & BG II=IAHH- \\
\hline 5 & IAHH-8005 BG II & I 3622 & 5 & -5.38 & 8.99 & 10.6 & 77 & 82 & 28 & Cross over & $\begin{array}{c}8041 \\
\text { BG I }=\text { IAHH-8083 } \\
\text { BG I>etc }\end{array}$ \\
\hline
\end{tabular}


Figure.1 AMMI I biplot based on seed cotton yield over main principal component (IPCA 1) values

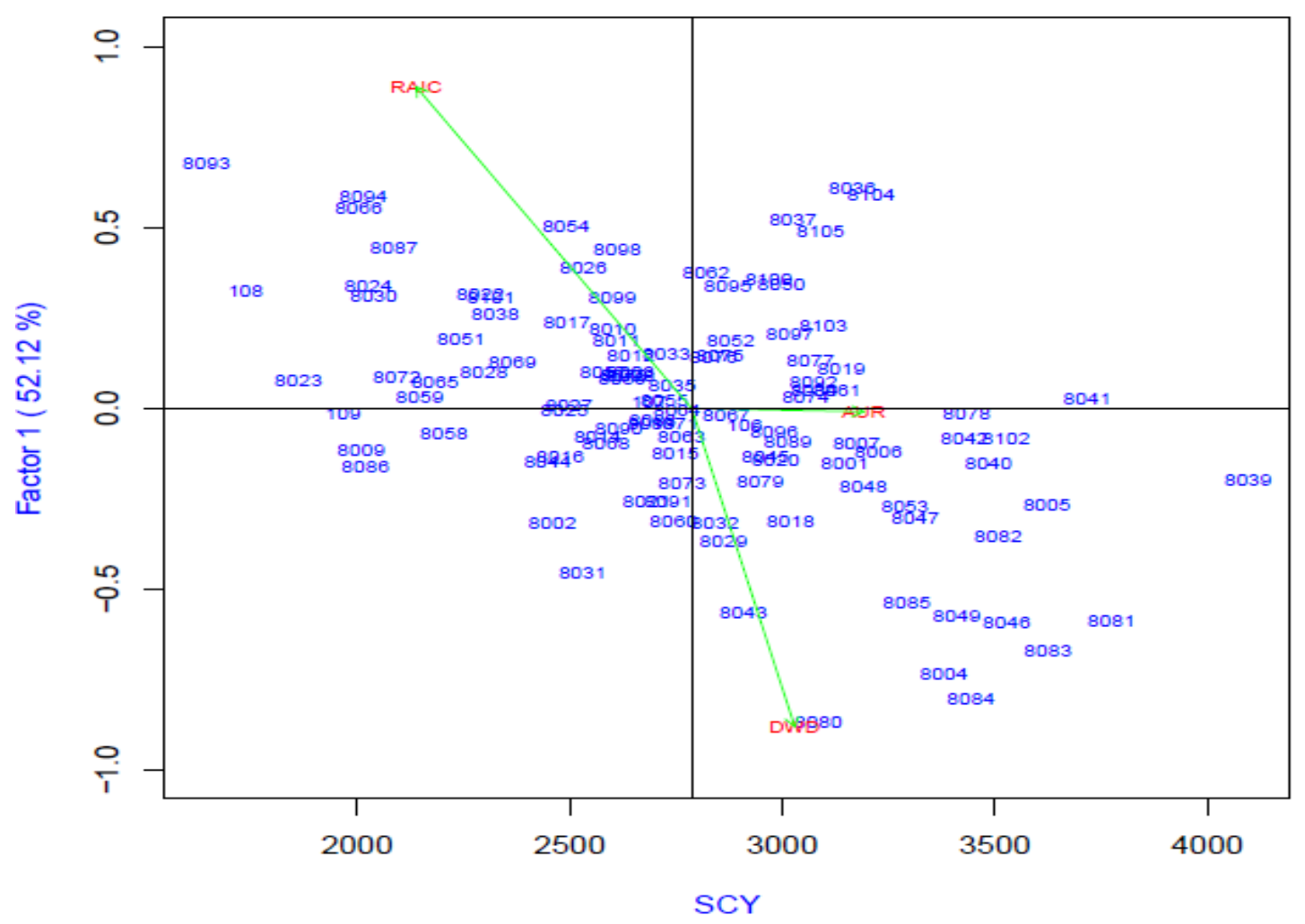

Figure.2 Vector view of GGE biplot derived for the relationships among the environments for the cotton yield (a. Environmental relation. b Average Environment coordination)

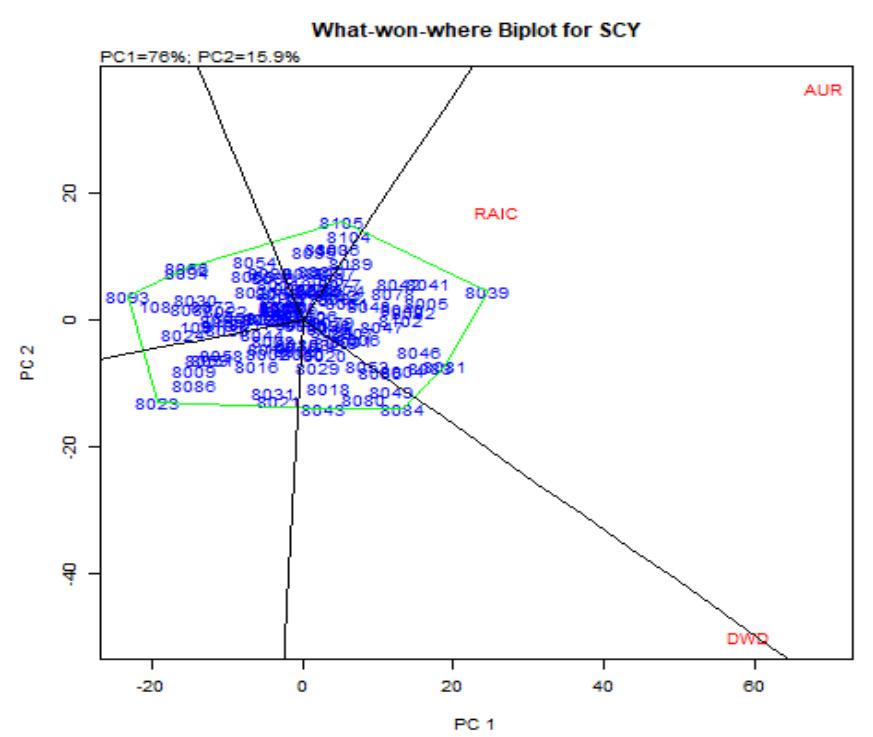

a.Environmental relation binlot

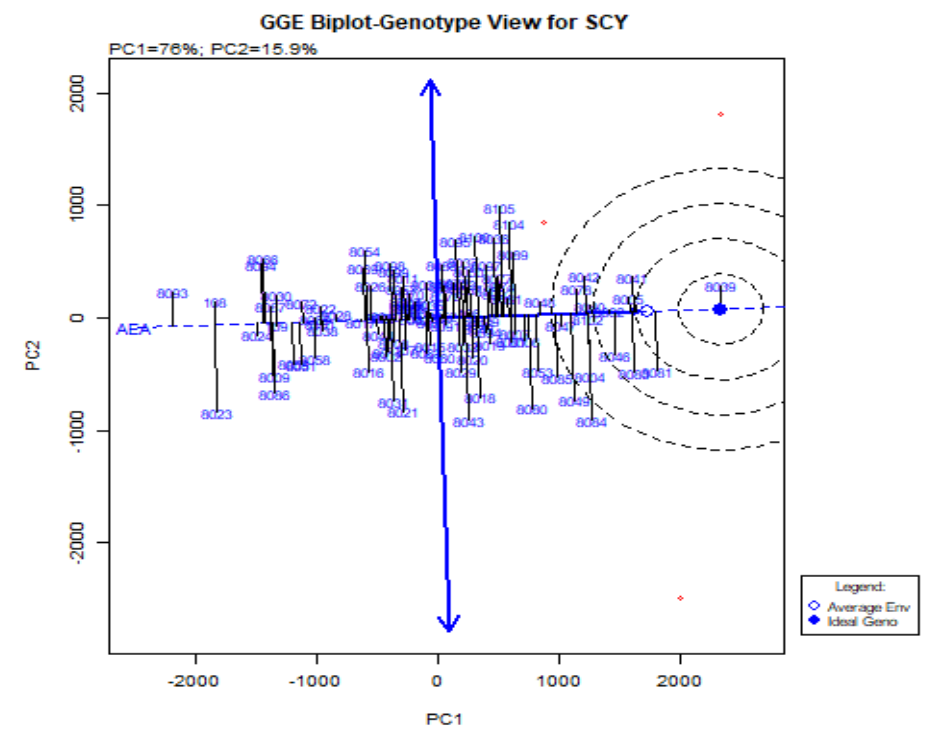

\section{b. Discriminating Vs Representative view of GGE biplot}


Figure.3 GGE biplot derived from the cotton yield over 3 environments (a. which-won -where won; b. Mean Vs Stability)

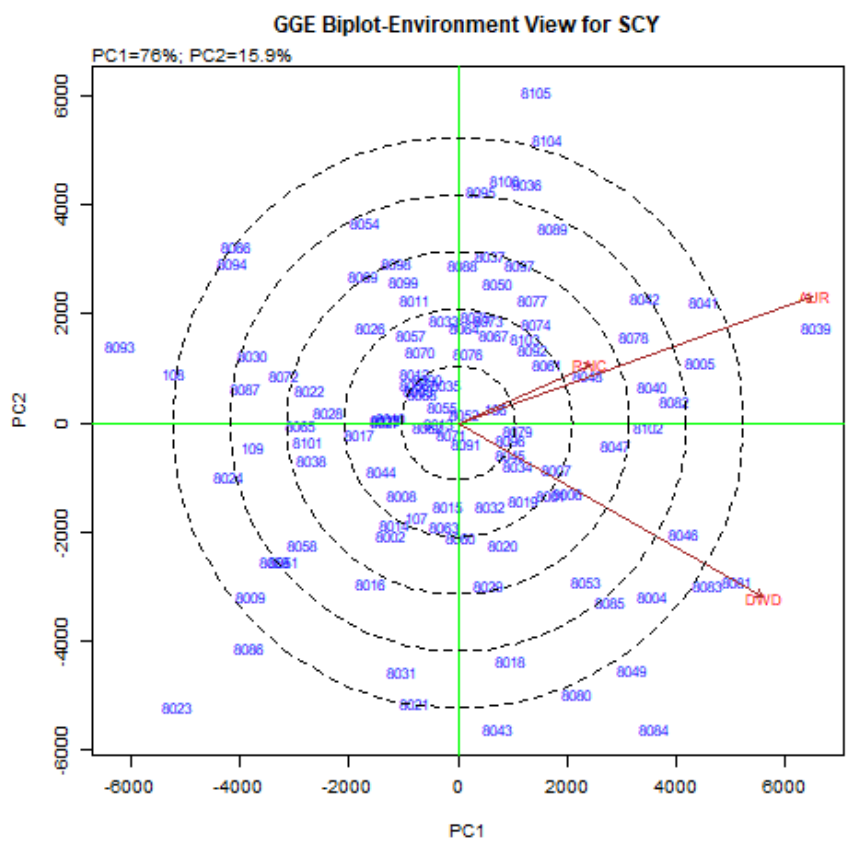

a. Which- won -where- won

In conclusion, the utilization of biometric tools in the decision making of hybrids for commercialization is a vital approach in addition to field visits and visual observations. Biometric tools such as AMMI and GGE biplot are most widely used to assess the stability of cotton genotypes across the environments. In AMMI analysis sum of squares towards GEI more compare to GGE $(81.9 \%)$ and differentiate the relationship with environment. When we consider top 5 high seed cotton yielding, GGE biplot proved more user-friendly and it was in line with the decision making process of the crop breeding and product development group. GGE biplot gave stable hybrids with high yield which were discriminated by biplot whereas in AMMI analysis the same hybrids with high yield had lower rankings. In GGE biplot, environments will be divided into clusters and after continuous evaluation, we can divide

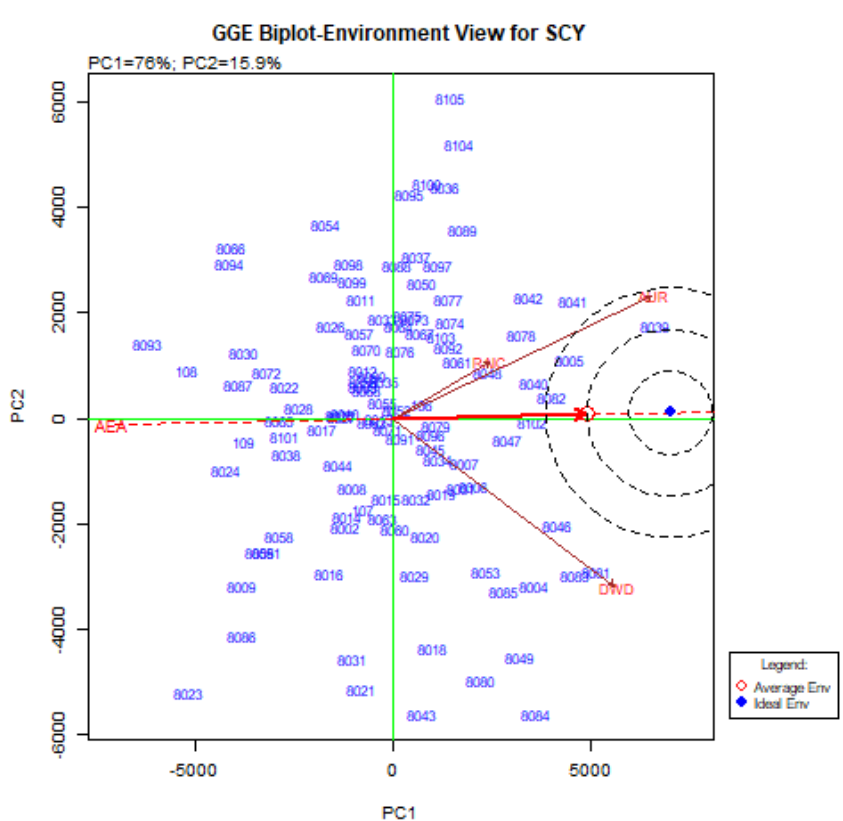

b. Mean vs stability biplot

into mega environments. So that redundant locations will be avoided using GGE biplot. In GGE biplot interaction with location and winning genotypes in specific location explained very less time and can be used in commercialization of location specific hybrids as well. In the study it was clear that Bt cotton hybrids had higher yield levels compared to non $\mathrm{Bt}$ cotton hybrids and in overall situation BG I hybrids were more promising than BG II. However, hybrids varied for stability pattern reflecting that $\mathrm{Bt}$ gene only contributes recovery of losses due to bollworms and makes it higher yielding and has no contribution to the stable performance of the hybrids.

\section{Acknowledgments}

The authors would like to thank to Chairman and Managing director of Indo-American 
Hybrid Seeds (I) Pvt Ltd. India for facilitating the experiments and financial support.

\section{References}

Alemu, G., Hussein, M., Dawit, A. and Tesfahun, A. 2019. Additive Main Effect and Multiplicative Interaction Analysis of Grain Yield of Advanced Bread Wheat (Triticum aestivum L) Genotype in Ethiopia. Journal of Agriculture and Horticultural Research 2 (1): $1-6$.

Blanche S.B. and Myers, G.O. 2006. Identifying discriminating locations for cultivar selection in Louisiana. Crop Sci 46: 946-949

Baxevanos, D., Goulasb, C., Rossic, J., and Braojosc, E. 2008. Separation of cotton cultivar testing sites based on representativeness and discriminating ability using GGE biplot. Crop Sci., 100:1230-1236.

Crossa, J., Gauch, H.G., Zobel, R.W. 1990. Additive main effects and multiplicative interaction analysis of two international maize cultivar trials. Crop Sci., 30: 493500.

Ebdon, J.S and Gauch, H. G. 2002. Additive main effect and multiplicative interaction analysis of national turf grass performance trials: I. Interpretation of genotypexenvironment interaction. Crop Sci., 42: 489-496

Gauch, H.G. and R.W. Zobel. 1996. AMMI analysis of yield trials. In: Kang M.S, Gauch HG (eds) Genotype by environment interaction. CRC Press. Boca Raton, FL.

Gauch, H.G. 2006. Statistical analysis of yield trials by AMMI and GGE. Crop Sci 46:1488-1500

ISAAA. 2018. Global Status of Commercialized Biotech/GM Crops in 2018. ISAAA Brief No. 54. ISAAA: Ithaca, New York.
ISAAA/ GM Approval database for MON531 and MON15985 events https://www.isaaa.org/gmapprovaldatab ase/event/default.asp?EventID=54\&Eve $\mathrm{nt}=$ MON531

Li, W., Yan, Z.H., Wei, Y.M., Lan, X.J., Zheng, Y.L. 2006. Evaluation of genotype $x$ environment interactions in Chinese spring wheat by the AMMI model, correlation and path analysis. Journal of Agronomy and Crop Science 192: $221-227$.

Mohammadi, R., Abdulahi, A., Haghparast, R. and Armion, M. 2007. Interpreting genotype $\mathrm{x}$ environment interactions for durum wheat grain yields using nonparametric methods. Euphytica, 157: 239-251. http://dx.doi.org/10.1007/s10681-0079417-3.

Orawu, M., Gladys, A., Lastus, S., George, O., Chris, O. 2017. Yield stability of cotton genotypes at three diverse agroecologies of Uganda. Journal of Plant Breeding and Genetics 5:101-114.

PBTools. 2014 Biometrics and Breeding Informatics, Version 1.4. PBGB Division. International Rice Research Institute, Los Banos, Laguna.

Purchase, J.L., Hating, H., van Deventer, C.S. 2000. Genotype X environment interaction of winter wheat (Triticum aestivum L.) in South Africa: II. Stability analysis of yield performance. S. Afr. 1. Plant Soil 17: 101-107.

Riaz, M., Naveed, M., Farooq, A., Mahnood, A., Rafiq, C.M., Nadeen, M., Sadiq, A. 2013. AMMI Analysis for stability, adaptability and GE interaction studies in cotton (Gossypium hirsutum L.). J Anim Plant Sci. 23:865-871

Riaz, M., Jehanzeb, F., Saghir, A., Muhammad, A., Waqas, S. C., Maria, A., and Riaz, A. K. 2019. Stability Analysis of Different Cotton Genotypes under Normal and Water-Deficit 
Conditions. Journal of Integrative Agriculture. 18(6): 1257-1265

Samonte, S. O. P. B., L. T. Wilson, A. M. McClung, and J. C. Medley. 2005. Targeting cultivars onto rice growing environments using AMMI and SREG GGE biplot analysis. Crop Sci., 45: 2414-2424

Tena, E., Goshu, F., Mohamad, H., Tesfa, M., Tesfaye, D. and Seife, A. 2019. Genotype $\times$ environment interaction by AMMI and GGE-biplot analysis for sugar yield in three crop cycles of sugarcane (Saccharum officinirum L.) clones in Ethiopia, Cogent Food \& Agriculture, 5:1, 1651925

Yan, W., L.A. Hunt, Q. Sheng, and Z. Szlavnics. 2000. Cultivar evaluation and mega- environment investigation based on the GGE biplot. Crop Sci., 40:597-
605.

Yan, W. and Hunt, L. A. 2001. Genetic and environmental causes of genotype by environment interaction for winter wheat yield in Ontario. Crop Sci., 41:19-25.

Yan, W. and M.S. Kang.2003. GGE biplot analysis: a graphical tool for breeders, geneticists and agronomist. CRC Press, Boca Raton, Florida, $271 \mathrm{pp}$.

Yan, W., M.S. Kang, B. M.A, S. Woods, P.L. Cornelius. 2007. GGE Biplot vs AMMI analysis of genotype-by- environment data. Crop Sci., 47: 643-53.

Yan, W., and J.B. Holland. 2010. A Heritability-Adjusted GGE Biplot for Test Environment Evaluation. Euphytica $171 \quad$ (3): 355-69. https://doi.org/10.1007/s10681-0090030-5.

\section{How to cite this article:}

Ashwini N.R. Samak, S. Rajeswari, R. Ravikesavan, N. Subbalakshmi Lokanadhan, N. Ganapathy and Kini, A.V. 2020. Comparison of AMMI and GGE Biplot Analysis to Assess the Adaptability and Stability of Bt Cotton Genotypes. Int.J.Curr.Microbiol.App.Sci. 9(09): 26722681. doi: https://doi.org/10.20546/ijcmas.2020.909.333 